\title{
Investigation on the Status Quo of Job Burnout of Physical Education Teachers in Colleges and Universities
}

\author{
Yanfei Yu \\ College of physical education, Tonghua Normal University, TongHua, Jilin, China
}

Keywords: Local Colleges and Universities, Physical Education Teachers, Job Burnout.

\begin{abstract}
In this paper, the burnout of physical education teachers in colleges and universities as the research subject, first of all, the adverse impact on the local colleges and universities sports teachers' occupation burnout phenomenon from three aspects are analyzed, then, starting from the three different dimensions, analyzes the reasons, resulting in local colleges and universities sports teachers' occupation burnout phenomenon at the end of the article. Put forward specific countermeasures of occupation burnout from four different aspects. Hope this research can provide useful reference for the positive related professional in leadership and experts.
\end{abstract}

\section{Introduction}

In recent years, the local colleges and universities education form and management mode of a huge change, with also appeared many ills, education and teaching management, especially the local college PE teachers' occupation burnout phenomenon has aroused widespread concern of all parties. In general, the emergence of the phenomenon of occupation burnout discomfort but within a short duration of time. The external and long-term outcome of PE teachers, will not only affect the quality of physical education for their job burnout, but also for students, parents, schools and other parties to bring long-term negative side effects.

Therefore, the investigation of the local occupation burnout of P.E. teachers in Colleges and universities, has become an urgent problem of current higher education teachers' occupation burnout problem. And the sports teacher's occupation population has aroused the attention of scholars and experts. The topic of the sports teachers occupation burnout status and causes of the investigation analysis the local college student resources, adverse effects on the phenomenon of the sports teachers occupation burnout are analyzed, and gives the reasons of local colleges and universities sports teachers occupation burnout phenomenon, finally puts forward some countermeasures to deal with the occupation burnout, hope to provide some theoretical guidance for the college physical education teacher burnout phenomenon, in order to develop and enrich physical education teachers occupation burnout theory, provide the basis for promoting the healthy development of college physical education.

\section{An analysis of the adverse effects of job burnout among College Physical Education Teachers}

The sports teachers' occupation burnout refers to the physical education teachers for their work is not a long-term school and society should respect and support and lack of sense of achievement and tired of emotional indifference and the corresponding behavior. The main performance is: in the teaching work of depression, apathy, low sense of personal accomplishment, originated in the sports teachers a door is not essential public think, has nothing to do with the career course. Occupation burnout is both for work and for individual, the negative effects are very serious.

Adverse effects on teaching effectiveness. Teachers' physical and mental fatigue, understanding of students, education will reduce the capacity in the invisible, the students' psychological aid 
management guidance ability to maintain the spirit will become low. Of course, there is education, the teaching method is not flexible or abnormal phenomenon, become machinery at work, low working efficiency. Work ability decreased, will eventually lead to reduce the quality of teaching.

Pose a threat to the health of physical education teachers themselves. The negative influence on Teachers' occupation burnout is in many aspects, one is the body's ability to adapt and adjust ability will continue to decline, to sleep, nervous system, directly affects the health indicators, two adverse health conditions will inevitably bring about the bad mood, appeared in the teaching process to emotion, interest is not high, attention, attention to teaching unit, tough requirements cannot be achieved.

Adverse impact on the career choice of PE teachers. Once the emergence of the phenomenon of occupation burnout of the long term, will inevitably lead to teachers for their work, and even have great doubts about his own self-denial, become a habit of thinking. As a result, it will seriously affect the teachers' occupation of their position to realize their own value and confidence. The sports curriculum has not been the mainstream school curriculum therefore, physical education teachers, it is difficult to appreciate the teachers as the people's sense of honor and mission, and occupation burnout more deeply this misunderstanding.

Have a negative influence on the development of interpersonal relationship. The loss of the mainstream value brought by the concept of occupation burnout and positive spirit orientation, will come into contact with students to work in the direct impact of contact with friends in life, this kind of negative thinking will often make people deal with things with more negative way, resulting from interpersonal tension, cause the work of harmonious atmosphere in destruction.

\section{The causes of job burnout among College Physical Education Teachers}

There are many reasons for the burnout of school physical education teachers. Through investigation and analysis, the paper summarizes the reasons for the existence of the ubiquitous sports teachers and summarizes them as follows:

High external pressure. At present, the community of teaching in higher education a higher degree of concern, although different from the culture of sports discipline class, but still has more discussion. Mainly based on expectations China traditional educational philosophy on this special occupation of teachers is too high, resulting in the teacher occupation "sacred", instead of teachers brought heavy psychological pressure. With the media information transmission speed, the slightest mistake, the teacher will become the hot spot in the teeth of the storm.

Sports teachers' pay and income do not match. In ordinary universities, sports is not the mainstream subjects, but teachers hard work but also not a few, because of many reasons system, the treatment of teachers is not high, the rise and development of the occupation channel is not smooth, welfare and promotion space cannot be compared with the cultural course teacher, so which part of the physical education teachers occupation burnout phenomenon appeared.

Psychological counseling is not enough. PE teachers in the occupation career environment in the long term, will inevitably lead to psychological discomfort, if teachers do not have their own to solve this problem, we need the school from the perspective of caring staff to help, for example: enterprise EAP assistance program, so that teachers can through scientific and effective means of rapid correction of psychological problems. At present local universities, in this configuration are blank, it will be a direct result of the occupation burnout phenomenon appears at the same time cannot be resolved.

The negative impact of students and the environment. The influence caused by occupation burnout and from school organizations at all levels and students of PE teachers in Colleges and universities. First of all, is in the process of teaching, students have become a serious problem, such as physical education students lack of interest, lack of initiative, uneven students learning ability, affected by the bad influence of social ethos, ideological work is difficult, and the relationship between PE teachers is weak to PE teachers has brought great pressure. Secondly, the teachers are engaged in professional sports in the school at the edge of the state, subject to the development of a 
major breakthrough in the development of the school, also always give priority to the main subjects of the school, the school sports teachers obtain limited resources few opportunities, so that physical education teachers in the title promotion outwards in a weak position. These factors have led to the teachers' occupation burnout.

\section{Some countermeasures for coping with job burnout}

Starting from their own ideas to do overall ascension. Relatively speaking, physical education teaching work is long repetitive, monotonous, lack of innovative work, physical education teachers in the face of discipline development is not balanced, attention degree is not enough, the future development of the lack of practical difficulties, should first from their own efforts. First of all, from the education and teaching reform to adjust your brains the increase of education teaching work, innovation and sustainable development efforts, individual education and teaching ideas into one to promote the work; secondly, to actively adjust and change the negative attitude of existing, with a positive angle to communicate with the students, focus on students' progress and growth, love the work of every detail and process, completely change the traditional status between teachers and students, to realize the harmonious development and win-win; thirdly, we must be good at summing up, finishing, mining slight surprise, for example, a sports teacher, Ping When you go to collect all kinds of teaching in the process of intravenous drip, with electronic album software to make beautiful little links, greatly regulate the classroom inside and outside the cheerful atmosphere, for yourself to win a high degree of attention and praise

Make adjustments from your own mentality. One of the occupation burnout weapon customer is positive and optimistic, happy state of mind, which requires physical education teachers to focus on the mental health level of their own. In general, can be adjusted from the following aspects: first, to have enough tolerance in dealing with some things, not high standards blindly or strict requirements, easy to bring their own troubles, but also easy to get along with the surrounding environment deteriorated easily; secondly, the teachers should distinguish between work and life, rigid and elastic, rigid and flexible between the degree, not only to assess the situation, targeted, but also to local conditions, flexible, to prevent the emergence of a road went black again, everything; to go to comprehensive evaluation, cannot focus too much on one point, cannot simply enlarge their own shortcomings, improperly belittle oneself, cannot be blind to see their advantages, only to ensure stable empty everything, Cheerful, self-confident self-status, in order to truly achieve the shaping of the sun mentality

Varied in its own way. The survey shows: the rich and colorful extracurricular activities can be a good initiative to mobilize people, regulate the sports teachers to know how to work the self-business life, looking for their own hobbies, to adjust the outside of work as a positive and beneficial supplement to their daily work. Through the movement the way to relax your mood, also can be released to express their ideas through a variety of information, but also through social activities beneficial to relax the mood, in a similar way, further expand their vision and mind, so as to effectively avoid the occupation burnout phenomenon.

Starting from self-cognition to make self-identity. Physical education should strive to combine the discipline characteristics of itself, improve self-identity and sense of self-efficacy. Among them, the so-called self-identity, is to have an objective and fair evaluation of their career, the so-called self-presence, to the value of their own clear positioning and development planning ideas and thoughts, the so-called self-efficacy, is to have a subjective sense to work on their own. For example: the result of teaching, scientific research achievement, students and parents and educators on social evaluation and so on. Only the above mentioned "three sense" in kneading together, in order to self-cognition to improve to a new level, to solve the occupation burnout phenomenon from a deeper level.

Enhance the knowledge connotation and strengthen the sense of professional role identification. Knowledge is a human mind, ideas directly or indirectly. By improving the connotation of knowledge, strengthen the role of occupation identity, to recognize the work of PE teachers the significance, and consciously to find their own shining points. Through the connotation 
of improving teachers' knowledge, strengthen their professional knowledge, a correct understanding of Physical Education teachers plays an important role in achieving the goal of school education, to promote teachers' professional growth, to alleviate the physical education teachers' job burnout can play a positive role.

\section{Conclusion}

The local college PE teachers' occupation burnout is not only a local phenomenon, is also the whole social phenomenon, it reflects the teachers team construction and management process of exposed teaching reform of university education in our country the problem of highlights from the side of PE teachers in this particular occupation in the development of defects and deficiencies from the system. The reasonable adjustment in practice to promote, from the case analysis, from the overall arrangement, that can effectively solve the current problems of further deterioration of occupation burnout of local colleges and universities, to draw the outline of the new channel of PE Teachers' occupation development, to stimulate the industry, dedicated, professional the working state, thus completely show the teachers of local colleges and universities in China a new style of work.

\section{Acknowledgments}

This research is supported by the education of Jilin province "in 13th Five-Year" plan key project: Investigation on the status quo of job burnout of physical education teachers in local colleges and universities and Countermeasures(DZ17115).

\section{References}

[1] Maslach C, Jackson S E. The measurement of experienced burnout. Journal of Occupational Behavior, 1981.

[2] Chen Ying. Review and Prospect of research on Job Burnout of teachers in China [J]. Journal of Teaching and Management.2011,18.

[3] Huang Wei. Study on Job Burnout of secondary vocational teachers and Countermeasures -Taking Huizhou secondary vocational school as an example, [J]. Computer Knowledge and Technology. Vol.11, No.35, December 2015.

[4] Zhou Jing. Cause analysis and countermeasure research on burnout of college physical education teachers [J]. Contemporary Sports Technology. 2015, 35

[5] Zou Xuan. Study on intervention strategies for job burnout of teachers in Jingzhou independent college [D]. Yangtze University.2015.

[6 Li Xiaotong. Influence factors and Countermeasures of job burnout among university teachers in Shaanxi [D]. Xi`an University of Architecture and Technology.2015. 